ISSN: 1130-3743 - e-ISSN: 2386-5660

DOI: http://dx.doi.org/10.14201/teoredu2016282185200

\title{
OPERACIONALIZACIÓN E INDICADORES DE LA PEDAGOGÍA DE LA ALTERIDAD
}

\author{
Construct operate of Pedagogy of Alterity
}

\section{Fonctionne et indicateurs de la Pédagogie de l'Alterité}

\author{
Cecilia Osuna Lever, Karla María DíAz López y Maricela LóPez Ornelas \\ Colegio de Ciencias Sociales y Humanidades. Sistema CETYS Universidad. \\ Camino a Microondas Trinidad km 1. Las Palmas 3. ${ }^{\text {ra }}$ sección. \\ Ensenada, BC. México. CP 22860. \\ cecilia.osuna@cetys.mx; karla.diaz@cetys.mx; ornelas67@gmail.com
}

Fecha de recepción: enero de 2016

Fecha de aceptación: marzo de 2016

\section{RESUMEN}

El presente artículo no pretende orientarse en la profundización filosóficoantropológica de la Pedagogía de la Alteridad, cuyo sustento teórico se remonta a los planteamientos de Lévinas, Horkheimer, Adorno y Pedro Ortega. Ni pretende abonar elementos teóricos a dicho constructo, sino que aporta un modelo categorial construido según los planteamientos que lo forman. La importancia de esta aportación radica en que el modelo categorial permite hacer operativos los elementos del discurso, para ser utilizados en la construcción de instrumentos en estudios empíricos. El modelo está conformado por una metacategoría o variable principal -pedagogía de la alteridad- y cuatro categorías: perfil del profesor, perfil del alumno, función de la escuela y función de la familia, con sus características e indicadores, que son el insumo para el diseño de instrumentos de recolección de datos.

Palabras clave: Pedagogía de la Alteridad; categorías; diseño de instrumentos. 


\section{SUMMARY}

This article does not focus on the philosophical-anthropological aspect of the Pedagogy of Alterity, which is based on the ideas of Lévinas, Horkheimer, Adorno and Pedro Ortega. Nor does it aim to add theoretical elements to said construct. It presents a categorial model built using the ideas that form the construct as a foundation. The importance of this contribution lies on the fact that the categorial model allows making operational the discourse elements, so that they can be used in the construction of instruments in empirical studies. The model is formed by a metacategory or main variable, which is the pedagogy of alterity, and four categories: professor profile, student profile, function of the school and function of the family, with their characteristics and indicators, which are the elements used to design data collection instruments.

Key words: Pedagogy of Alterity; category; assessment design.

\section{SOMMAIRE}

Cet article n'est pas destiné à l'étude philosophique-anthropologique de la Pédagogie de l'Altérité, dont le fondement théorique remonte aux idées de Lévinas, Horkheimer, Adorno et Pedro Ortega. Son but n'est pas de payer cette construction des éléments théoriques, mais d'apporter un modèle catégorique construit sur la base des idées qui forment cette construction. L'importance de cette contribution est que le modèle catégorique permet l'exploitation des éléments du discours, à utiliser dans la construction d'instruments dans les études empiriques. Le modèle est composé d'un meta-categorie ou variable principal: pédagogie de l'altérité, et quatre catégories: profil du professeur, profil de l'élève, la fonction de l'école et le rôle de la famille, avec ses caractéristiques et ses indicateurs, qui sont l'entrée pour le conception d'instruments de collecte de données.

Mots clés: Pédagogie de l'Altérité; catégories; conception de l'instrument.

\section{INTRODUCCIÓN}

El presente artículo, que surge como resultado de una discusión conceptual hace dos años con los profesores Pedro Ortega Ruiz y Ramón Mínguez Vallejos, no pretende orientarse a la discusión filosófico-antropológica de la Pedagogía de la Alteridad, ni de los elementos que la configuran. Tampoco pretende abonar teóricamente dicho constructo ni hacer una crítica profunda, puesto que ya existen algunos aportes en la literatura orientados hacia ello; lo que no hemos encontrado son trabajos que intenten transferir dichos elementos teóricos al ámbito de lo empírico. Por lo que el objetivo fundamental de este trabajo es utilizar los referentes teóricos de la Pedagogía de la Alteridad y transferirlos al campo metodológico para ofrecer una propuesta de modelo categorial que coadyuve a la operacionalización de 
dicha variable, con objeto de facilitar el diseño de instrumentos de recolección de datos para proyectos de investigación de corte cualitativo o cuantitativo, en los que se deseen identificar expresiones de esta pedagogía en espacios educativos concretos.

El desarrollo de la Pedagogía de la Alteridad se ha venido haciendo en los últimos años, habiendo sido particularmente el profesor Ortega Ruiz quien ha fortalecido el discurso filosófico y antropológico que lo sustenta y, junto con el grupo de investigación de Teoría de la Educación de la Universidad de Murcia, ha buscado explicar categorías asociadas a dicha pedagogía, como la familia, la escuela, el profesor y otras. Su discurso es esencialmente pedagógico y pretende responder a una pregunta fundamental en educación: para qué educar. Encuentra la respuesta en la filosofía de Emmanuel Lévinas y en los planteamientos socioeducativos de la escuela de Fráncfort, en particular de Adorno. El discurso de la Pedagogía de la Alteridad tiene profundas raíces idealistas, pues sugiere un perfil ambicioso que delinea a un profesor que debe acoger al otro (al alumno) y compadecerse de él, sin perder de vista su contexto. Como antecedente filosófico de este discurso, se encuentran, por un lado, los planteamientos de Hannah Arendt, quien ha abordado el discurso humanista del dolor y de la injusticia humana, y, por el otro, los planteamientos sobre la marginalidad, la opresión y la pedagogía de la esperanza de Paulo Freire.

Como ya se indicó líneas arriba, este texto define como variable principal al constructo pedagogía de la alteridad, asignándole la clasificación de metacategoría general de análisis, de la que se desprenden varias categorías que conforman dicho discurso pedagógico. Esta clasificación de los elementos del discurso permite operacionalizar su contenido para utilizarla en estudios de corte empírico y describir la realidad de escuelas, del trabajo del profesor, de la relación familia-escuela, profesor-alumno, entre otras. Y así, a partir de la explicación de la realidad, poder generar proyectos de intervención diseñados específicamente para lograr un impacto que transforme la realidad, generando relaciones de mayor impacto formativo en los centros escolares.

\section{ANTECEDENTE}

El discurso de la Pedagogía de la Alteridad como propuesta educativa tiene sus orígenes en los inicios de la década de los noventa. Surge como una línea en desarrollo del Grupo de Investigación en Educación y Valores de la Universidad de Murcia, España (Ortega, 2014). La Pedagogía de la Alteridad está cimentada en la ética de la compasión de Emmanuel Lévinas, que parte de la premisa de considerar al otro (ser humano) en su necesidad. Ortega traslada este concepto central al acto educativo y establece que, para educar, es preciso escuchar y atender a la pregunta del otro (el estudiante). Al respecto, Ortega $(2010,15)$ expresa que «si educar es responder, la respuesta no se da a un individuo sin rostro y sin entorno, sino a alguien». Este planteamiento reivindica la importancia del ser humano que 
se está educando, pues, a decir de Ortega (2014), en la actualidad (y de acuerdo al privilegio que se da a la formación tecnocrática en los escenarios educativos) ha sido imposible acercarse y conocer al sujeto (alumno) que tenemos delante.

Dado que el acto educativo es fundamentalmente una actividad social (de seres humanos y para seres humanos), los protagonistas de dicho acto deben centrar su atención en el sujeto en formación y valorar y legitimar su presencia. La exigencia ética en la educación no emerge del yo, sino del otro u otra, cuya presencia nos obliga a actuar. Es por ello que nuestro yo se define, desde nuestra responsabilidad para con los demás, como algo intrínseco a su presencia y no sujeto a la libre elección (Lévinas, 1991). Y entonces, de acuerdo a la respuesta que demos a la llamada del otro, definiremos nuestro grado de compromiso ético hacia él.

\subsection{El origen: la ética de la compasión}

A diferencia de la ética kantiana, que se fundamenta en principios universales muy generales para normar la conducta humana, la ética de la compasión se basa en la necesidad ineludible de responder del otro en su contexto individual y su situación concreta de necesidad, es decir, practicar la compasión por el otro. Los exponentes más representativos de estos conceptos son Shopenhauer y Lévinas. La ética de la compasión parte del supuesto de que la necesidad del otro nos debe afectar, nos debe mover a responder de él. Por su parte, Mèlich $(2010,230)$ plasma como ejemplo de este concepto el relato bíblico del buen samaritano, que siendo de Samaria y a pesar de que en ese momento existían rígidas normas en contra de la convivencia entre judíos y samaritanos, deja a un lado dichas normas y no se sitúa en el ámbito del «deber ser» de acuerdo a las regulaciones de la época, sino que se detiene, siente compasión por el otro que está en necesidad, lo ayuda y aún va más allá al despojarse de su dinero para dejar pagado el sustento y la recuperación del hombre necesitado. A decir de este autor, si el samaritano hubiera actuado en concordancia con los principios morales que regían en aquella época, nunca se hubiera detenido a ayudar al hombre herido. Es así como la compasión hacia el otro no se sitúa en el ámbito del "deber ser", sino que el samaritano se conmocionó en su interior y actuó respondiendo del otro conforme a lo que el otro estaría esperando: su compasión, su ayuda. Por otro lado, Ortega indica que la compasión establece una relación ética, implicando la responsabilidad entre el que compadece y el compadecido y "que solo queda saldada cuando el otro recupera su dignidad» (2014, 12). Sin embargo, como enuncian Gárate y Ortega (2013), la compasión, desde la postura de Lévinas, se entiende como responsabilidad con lo que no es asunto de uno o que incluso no nos concierne, pero aun así es abordado por uno. No es una postura que se deba reducir a ayudar a los excluidos por la sociedad, sino que debe ir más allá, debe ser un modo ético de relación con el otro, reconociendo, de manera práctica y no solo discursiva, la dignidad inviolable del otro. En este sentido, Lévinas refirió que: 
Desde el momento en que el otro me mira, yo soy responsable de él, sin siquiera tener que tomar responsabilidades en relación con él, su responsabilidad me incumbe. Es una responsabilidad que va más allá de lo que hago (1991, 90).

En este planteamiento se enfatiza la capacidad de respuesta que tenemos hacia el otro, dejando implícito un compromiso firme y sostenido, que atienda su necesidad. Hasta aquí se sustenta el origen de la ética de la compasión, pero ¿cómo estos preceptos se involucran o trasladan al ámbito educativo? La Pedagogía de la Alteridad tiene como fundamento teórico-filosófico la ética material de Lévinas antes descrita, pero se enriquece también de planteamientos de Horkheimer y Adorno, y del propio Ortega (Ortega, 2006). La acción educativa, desde esta perspectiva, propone la acogida al otro, escucharlo, cuidarlo, responder al otro, desde la responsabilidad del docente hacía el estudiante con una exigencia de incondicionalidad (Ortega, 2016). Es decir, un nuevo modo de acercarse y entender al hombre que se educa. Es una propuesta educativa que implica trasformar la forma de entender la enseñanza y el compromiso que tenemos ante el educando, más allá del centro educativo. «Es una nueva manera de vivir que se entiende desde el otro, con el otro y para el otro" (Ortega, 2014, 30). Es un planteamiento complejo y retador, pero posiblemente una alternativa necesaria en el ámbito educativo que enfrentamos en el contexto actual, caracterizado muchas veces por relaciones interpersonales frías y distantes.

La relación educativa que se establece desde este enfoque es necesariamente contextual, es decir, se lleva a cabo en un tiempo y en un espacio determinados. Esto refiere que, al educar, se debe considerar la situación particular del educando, sus circunstancias, el momento que atraviesa, su contexto familiar y social, pues, a decir de Ortega $(2014,20)$, "no se educa en tierra de nadie». Por tanto, en las escuelas educamos a seres con rostro y contexto. Cuando el profesor se involucra en el contexto del educando, se logra una especie de vínculo que permite que la acción educativa sea significativa para el estudiante, evitando caer en la simple práctica de una retórica vana y sin sentido o de una manipulación educativa. La Pedagogía de la Alteridad no considera a un sujeto indefinido, universal o réplica de otros, sino que "en la relación educativa, la respuesta se da a un sujeto concreto y singular» (Ortega, 2014, 22). Este planteamiento va más allá de una postura meramente reduccionista que supone que el docente se debe enfocar solamente en qué enseñar (contenidos) y cómo enseñar (estrategias didácticas), porque ello hará difícil que el docente se ponga en el lugar del otro y responda de él. Ortega refiere que la educación en la alteridad implica memoria, pues los seres humanos contamos con un bagaje de experiencias y vivencias que nos hacen ser quienes ahora somos, e implica testimonio, pues la Pedagogía de la Alteridad más que "explicar» intenta "mostrar", ya que el educador transmite su experiencia de vida, su modo de relacionarse con los demás, así como su personalidad. En la Pedagogía de la Alteridad «la relación educador-educando es una relación ética basada en la experiencia-testimonio del mismo»(Ortega 2014, 29).

Como puede entenderse, según estos supuestos se configura una concepción muy particular de la educación; en esencia, educar se concibe como un acto de 
acogida y responsabilidad. Concretamente y desde la postura de Ortega (2011, 2016) reivindicar el carácter histórico del ser humano conlleva en educación varias exigencias: a) la educación es una tarea original, singular, no estandarizada, siempre inacabada, incierta y arriesgada; b) no se puede educar si no se conoce la situación y el momento (contexto) en que vive el educando, y c) no se puede educar en tierra de nadie, haciendo abstracción de las características singulares de cada educando, pretendiendo hacer una educación de validez universal. Estas tres premisas ponen el acento en la relevancia que tiene recuperar los fines de la educación y poner en su justo balance la importancia del ser que se está educando.

Este novedoso enfoque aplicado a la educación ha delineado en mayor o menor medida la conceptualización de los sujetos involucrados en el acto educativo. Así, la Pedagogía de la Alteridad trata de definir idealmente la relación docente-alumno, el papel del docente, el rol del estudiante, de la familia y de forma incipiente la función del centro escolar en el proceso educativo, personajes todos que ineludiblemente se deben involucrar en el acto de educar. A pesar de que este enfoque se encuentra aún en desarrollo, a continuación describiremos algunas características que están ya bien definidas en torno a dichos protagonistas.

\subsection{Perfil del educador}

El profesor debe aprender a mostrarse dispuesto, receptivo y, desde luego, encontrarse preparado para responder (tanto en conocimientos como pedagógicamente) a las demandas de una situación educativa en la que el otro reclama y llama. En palabras de Ortega $(2016,255)$, el educador debe sentir «el peso de tener que sostener al educandon; en consecuencia, el educador no puede renunciar a su función más primaria: ayudar al nuevo nacimiento de alguien que a su vez asuma responsabilidad de vivir no solo con los otros, sino también para los otros en sociedad y para transformarla. Por tanto, en el marco de esta pedagogía, a los profesores es exigido prestar atención a las circunstancias concretas de cada alumno en su situación, en la experiencia singular de su vida, para poder ayudarle (educarle) en su proyecto de construcción personal. Dicha exigencia implica un cambio en la cultura de enseñar, una nueva filosofía de la educación en la que se rescate y dé prioridad a la situación ética, por lo que el alumno dejará de ser objeto de "conocimiento y control" para convertirse en el interlocutor necesario para el proceso de construcción personal (Ortega, Mínguez y Hernández, 2009). El educador debe acompañar, orientar, guiar, animar, facilitar y no suplantar al alumno, ni imponerle un determinado recorrido. Educar también implica que el profesor sea capaz de juzgar críticamente lo que está pasando en las condiciones de vida de sus alumnos, sin juicios a priori, y ser capaz, a su vez, de trasmitirles su experiencia vital, su modo de relacionarse y vivir con los otros, de resolver el problema de su existencia con los otros.

A manera de síntesis, podría afirmarse que el educador requiere ser consciente de su misión, en el sentido de procurar elementos críticos en su práctica educativa, no limitándose a ser solo un buen técnico de la enseñanza. Además, 
se requiere que el educador sea un humanista, lo que se traduce en apreciar la vida y el mundo en que le ha tocado vivir. Toda la descripción anterior implica un gran reto para el docente que solamente lo puede enfrentar si realmente tiene la vocación por la docencia. Es indudable que en la Pedagogía de la Alteridad el perfil del docente tiene amplia relevancia y es uno de los elementos que ha sido mayormente definido.

\subsection{Interrelación docente-estudiante}

El proceso educativo se inicia con la aceptación y reconocimiento entre el profesor y el estudiante, en la acogida gratuita y desinteresada que se presta al educando, para que este perciba que es alguien y que es reconocido en su singularidad personal. Por ello, desde la Pedagogía de la Alteridad, cuando hablamos de educación, estamos evocando un acontecimiento, una experiencia singular e irrepetible en la que la ética se nos muestra como un genuino suceso, en la que de forma predominante se nos da la oportunidad de asistir al encuentro con el otro, al nacimiento de algo nuevo.

Hay diversas investigaciones sobre las variables que influyen en los procesos de enseñanza-aprendizaje; sin embargo, en dichos estudios ha quedado soslayada la percepción que el profesor tiene sobre su relación de educador con el educando, a pesar de que su actitud ante él es una variable que influye en el proceso educativo si se pretende hacer «algo más» que trasmitir conocimientos y enseñar destrezas y habilidades (Ortega, 2011, 2016). Por consiguiente, el profesor es generador de un ambiente áulico que debe estar enmarcado en la confianza y aprobación mutua. Así, el docente debe hacerse presente en la vida de los educandos, desde experiencias valiosas, como alguien en quien se puede confiar. En este proceso el educando empieza a vivir la comprensión, el afecto y el respeto hacia la totalidad de lo que es, experiencia que puede ver plasmada también en sus compañeros de aula, porque ellos también son acogidos. Así, la acogida en educación es el reconocimiento por parte del educador hacia la alteridad del educando, de su dignidad inviolable; es salir de uno mismo para reconocerse en el otro. En palabras de Ortega (2011), la acogida y el hacerse cargo del otro es una actitud de «entrañas» que escapa a toda forma de planificación y control. Así pues, la Pedagogía de la Alteridad reconoce que un ambiente propicio dentro del aula que considere el contexto del estudiante, sus intereses y brinde un espacio de acogida favorecerá el acto de educar.

\subsection{Perfil del estudiante}

En esta aproximación, el estudiante es concebido como un ser activo, reflexivo, que busca y espera una respuesta. De acuerdo con Ortega (2011), en el aula la iniciativa no la tiene el profesor, proponiendo o imponiendo solamente determinados contenidos de un programa ya establecido, sino que la iniciativa surge del educando cuando solicita ayuda o acompañamiento en su formación personal; 
CECILIA OSUNA LEVER, KARLA MARÍA DÍAZ LÓPEZ Y MARICELA LÓPEZ ORNELAS OPERACIONALIZACIÓN E INDICADORES DE LA PEDAGOGÍA DE LA ALTERIDAD

cuando, desde su vulnerabilidad y necesidad, hace una pregunta en la esperanza de encontrar una respuesta de acogida. El estudiante suele implicarse, cuestiona y participa activamente en su educación y es un ser humano con un contexto y una vida determinados. Es un ser en crecimiento y formación que quiere saber y buscar el acompañamiento del profesor para que ello se facilite. Esta descripción recupera un rol más dinámico y diligente en el estudiante y no un ser pasivo sin voluntad y sin deseos de educarse y da mucha relevancia a la consideración de la condición humana y contextual del estudiante.

\subsection{Función de la escuela}

Otro de los elementos que aborda la Pedagogía de la Alteridad se refiere a la función de la escuela, pues es el entorno en el cual el estudiante se educa y que necesariamente influye directa o indirectamente en su aprendizaje. La institución educativa debe fomentar que los estudiantes desarrollen el juicio crítico para que puedan actuar como ciudadanos comprometidos y tomar decisiones sobre asuntos públicos, promover el interés por el bien social y la justicia distributiva (Ortega, 2014), todo lo cual se refleja a través del desarrollo de proyectos comunitarios escolares que beneficien a la sociedad. Es recomendable que la institución educativa considere el involucramiento de los padres de familia en el proyecto escolar de sus hijos y sensibilizarlos sobre su papel preponderante en su educación. Otro de los aspectos referido al centro escolar sugiere que se debe fomentar un clima moral como condición ambiental para el aprendizaje en general y en particular promover valores sociomorales. La moral es entendida como lo que nos hace responsables de los otros y de los asuntos que nos conciernen como miembros de una comunidad, empezando por el propio centro escolar. Es necesario un clima de afecto, de aceptación y complicidad entre el educador, el educando y las autoridades educativas. En consecuencia, la educación desde la alteridad tiene una necesaria dimensión social. Es ética y política, es compasión y compromiso, puesto que despojar a la educación de estas dimensiones es reducirla al más puro adoctrinamiento (Ortega, 2014). Este enfoque pone de relevancia el papel social de la educación, en términos de contribución a tres cuestiones: impulsar el fomento de valores morales, dar al estudiante el sentido de vida (tiempo y espacio) y dotar a los estudiantes de una promesa (Ortega, 2016).

\subsection{Función de la familia}

La familia es uno de los elementos de este enfoque que requiere mayor abordaje teórico, pues es indudable su relevancia (en conjunto con la escuela) en la socialización de las jóvenes generaciones mediante la interiorización de las normas, valores y patrones de conducta presentes en la sociedad. En nuestros días, están emergiendo nuevos esquemas familiares: monoparentales, segundas nupcias, uniones no matrimoniales, entre otras. Por lo tanto, la apropiación o interiorización de 
normas y valores ya no se da paralela a la socialización. Según Ortega (2011), pareciera que las instituciones, particularmente la familia y la escuela, se encuentran incapaces para realizar su función trasmisora de sentido. Pareciera que la familia ha dejado de considerar importante su función como agente formador de la vida sociocultural, biopsicosocial y escolar de los hijos (Hernández, 2014). Como consecuencia, tanto la familia como la escuela, que antes figuraban como referentes fundamentales en la construcción moral de los hijos, ahora son cuestionados y han entrado en competencia con otros agentes socializadores tanto humanos como virtuales. Basta considerar que el modo de socialización de las jóvenes generaciones se realiza básicamente en la experiencia grupal, y no tanto en la familia, la escuela $\mathrm{u}$ otras instituciones; esta autoconstrucción moral del joven se entiende como un agregado de sucesivas influencias en función del contexto (Ortega, 2011). En conclusión, en la Pedagogía de la Alteridad, la familia debe ser el espacio moral en el que los padres asumen su responsabilidad educativa y de acompañamiento y acogida hacia los hijos.

Dado que la familia es el hábitat natural para el aprendizaje-apropiación de los valores morales, concretamente el clima educativo de la familia es el que posibilita la apropiación del valor moral. Dicho aprendizaje exige la referencia a una experiencia suficientemente estructurada, coherente, continuada, que permita la exposición de un modelo de conducta expresada en el tiempo, no contradictoria o fragmentada. Con ello, para el hijo, en su familia, la acogida significa sentirse y saberse aceptado y querido, protegido y seguro por el amor y cuidado de sus padres, lo que a su vez implica apoyo, confianza, ternura, sentir acompañamiento, orientación y guía por parte de los padres (Ortega, 2011).

Por otro lado, la decisión sobre qué valores deben trasmitirse en el núcleo familiar depende del contexto y realidad particular de cada familia y, a su vez, se subraya la relevancia que tienen valores de convivencia social, cívica y aquellos otros relativos a las relaciones interpersonales, desde una pedagogía testimonial. Por lo tanto, los valores «se aprenden en y desde la experiencia de la acogida, de la donación y del acompañamiento de los adultos como narración y testimonio ante niños y adolescentes» (Hernández, 2014, 181). Como se puede observar, el papel de la familia como promotora de un clima moral y afectivo que favorezca el logro académico de los hijos es un elemento fundamental considerado también en este enfoque.

Pues bien, la primera aportación de este artículo tiene que ver con la clasificación o el "desmenuzamiento" de los elementos que conforman este constructo que acabamos de presentar: perfil del educador, la interrelación docente-estudiante, perfil del estudiante, función del centro escolar y función de la familia; la segunda es la configuración de un modelo categorial de orden conceptual para facilitar la operacionalización de dichos elementos en el diseño de instrumentos de recolección de datos, lo que constituye una aportación metodológica al estudio de este enfoque, que en la actualidad no se ha publicado en la literatura sobre el tema. Entendemos que todo ello resulta útil para trasladar este tipo de conceptos teóricos al campo de lo empírico, con objeto de describir e interpretar una realidad. 


\section{Modelo categorial para la Pedagogía de la Alteridad}

Antes de entrar de lleno en la parte metodológica, explicaremos brevemente qué es un modelo categorial. Cuando se pretende diseñar un instrumento para la recolección de datos (ya sea cuantitativo o cualitativo), se debe definir la "variable principal" o "metacategoría» de análisis, que refiere al constructo teórico que se quiere abordar para su estudio en el campo empírico. En este caso, la variable principal (o metacategoría) es la Pedagogía de la Alteridad. Una vez que se definió conceptual y teóricamente la variable principal, se deben desglosar sus componentes en dimensiones o categorías, es decir, todos los elementos conceptuales que conforman dicha variable. Posteriormente, se deriva la definición de una serie de indicadores para cada dimensión o categoría, que son el conjunto de características observables que serán el fundamento para redactar los ítems o preguntas (Creswell, 2009; Hernández, Fernández y Baptista, 2010). Todo ello constituye una especie de análisis conceptual-categorial para desmenuzar en sus elementos más finos el constructo que se pretende medir.

Así, en el caso que nos ocupa y de acuerdo al nivel de generalidad de los elementos teóricos que sustentan este enfoque, nuestro modelo propone una metacategoría principal: Pedagogía de la Alteridad y cuatro categorías: perfil del educador, perfil del estudiante, función de la escuela y función de la familia (Figura 1); a su vez, algunas categorías desprenden subcategorías de análisis. Además, cada uno de los elementos del modelo cuenta con sus características y descripción operacional de las mismas. Todo lo cual permite conformar una especie de tabla de especificaciones que será la base para la elaboración de los ítems (ver Tabla 1 más adelante).

FIGURA 1

Metacategoría y Categorías Que configuran la Pedagogía de la Alteridad

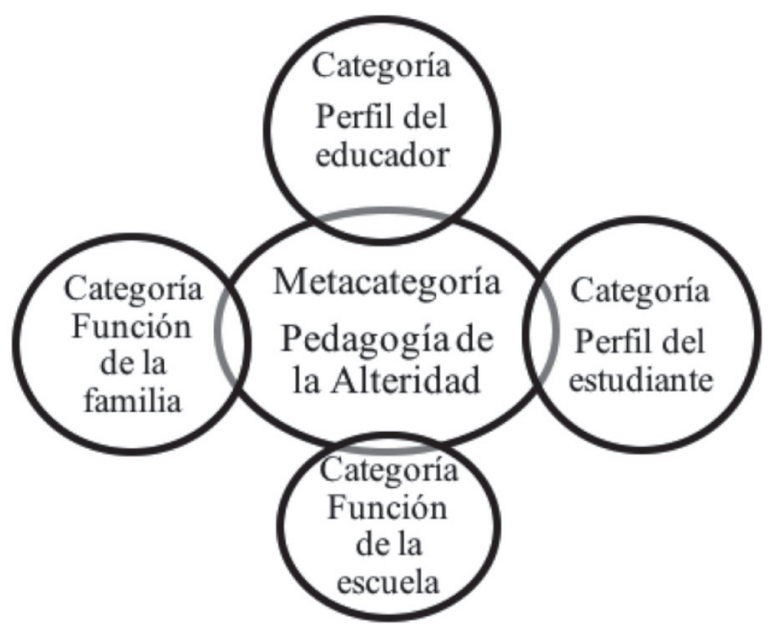


A continuación se presenta una breve descripción del modelo:

Metacategoría Pedagogía de la Alteridad. Es la variable principal que, en concreto, se define como un discurso pedagógico que toma como punto de partida la relación ética que se establece entre el educador y los educandos, por lo que las acciones educativas emprendidas por el educador se centran en el reconocimiento y responsabilidad por el otro (estudiante) y su singular contexto, lo que a su vez implica asumir responsabilidad ante él.

Categoría Perfil del Educador. Con base en el referente teórico, esta categoría describe el conjunto de elementos que delinean el perfil deseable del profesor y de ella se desprenden tres subcategorías: cualidades personales, relación interpersonal con el alumno y promotor de un clima moral en el aula. Todas son inherentes al papel del docente y cada una asume ciertas características que son descritas en un nivel más operacional.

Categoría Perfil del Estudiante. Abarca dos subcategorías: agente activo y ser contextual, que integran las características comunes al perfil del estudiante en la Pedagogía de la Alteridad y se describen con sus particularidades e indicadores.

Categoría Función de la Escuela. Esta categoría única retoma los elementos que se considera que debe recuperar la escuela en su responsabilidad comoagente que también educa.

Categoría Función de la Familia. Con tres subcategorías, que definen la función de la familia dentro de este enfoque, estableciendo pautas de comunicación, promotora de valores y su papel como elemento incidente del logro escolar de los hijos.

Éstas serían, pues, las categorías básicas para la construcción de un instrumento cuyo referente teórico principal fuera la Pedagogía de la Alteridad y transitar de ahí a sus dimensiones o componentes; posteriormente vendrán los indicadores y finalmente los ítems o reactivos que conformarán el instrumento. En este artículo presentamos una matriz de trabajo que configura la descripción extensa del modelo categorial con sus elementos, así como la definición de indicadores para cada categoría. Estos últimos sirven para elaborar ítems que pueden conformar el diseño de un instrumento de recolección de datos, pues representan todos los componentes del dominio de contenido de la variable principal: Pedagogía de la Alteridad. Y una vez que se tiene esta matriz, se pueden generar los reactivos y determinar los niveles de medición y codificación de los mismos o bien de las categorías de observación, según se trate de un instrumento cuantitativo o cualitativo (Creswell, 2009; Hernández, Fernández y Baptista, 2010). 
TABLA 1

\section{Modelo Categorial de la variable Pedagogía de la Alteridad}

\begin{tabular}{|c|c|c|c|c|}
\hline METACATEGoRía & CATEGORÍA & SUBCATEGORÍA & CARACTERISTICAS & INDICADORES \\
\hline \multirow{9}{*}{$\begin{array}{l}\text { Pedagogía de la } \\
\quad \text { Alteridad } \\
\text { Discurso } \\
\text { pedagógico } \\
\text { que toma como } \\
\text { punto de partida } \\
\text { la relación } \\
\text { ética que se } \\
\text { establece entre } \\
\text { el educador y el } \\
\text { alumno; por lo } \\
\text { que las acciones } \\
\text { educativas } \\
\text { emprendidas } \\
\text { por el educador } \\
\text { se centran en el } \\
\text { reconocimiento } \\
\text { del otro } \\
\text { (alumno) y } \\
\text { su singular } \\
\text { contexto, lo } \\
\text { que a su vez } \\
\text { implica asumir } \\
\text { responsabilidad } \\
\text { ante él. }\end{array}$} & \multirow{9}{*}{$\begin{array}{l}\text { Perfil del } \\
\text { educador }\end{array}$} & \multirow{4}{*}{$\begin{array}{l}\text { Cualidades } \\
\text { personales }\end{array}$} & $\begin{array}{l}\text { Ama la vida } \\
\text { Entusiasta }\end{array}$ & $\begin{array}{l}\text { Ama la vida y lo expresa con sentimientos de } \\
\text { gratuidad y gratitud. } \\
\text { Demuestra un genuino interés por su labor como } \\
\text { educador y por los estudiantes. }\end{array}$ \\
\hline & & & $\begin{array}{l}\text { Vocación } \\
\text { docente }\end{array}$ & $\begin{array}{l}\text { Es sentir la irrecusable llamada del otro en cuanto } \\
\text { que está necesitado de ayuda, de educación. }\end{array}$ \\
\hline & & & Compasivo & $\begin{array}{l}\text { Lo motiva acercarse al otro (el educando) que sufre, } \\
\text { que está indefenso. Trasciende de su egoísmo y } \\
\text { el centrarse en sí y para sí mismo. Se olvida de su } \\
\text { persona y está a disposición del otro. }\end{array}$ \\
\hline & & & Solidario & $\begin{array}{l}\text { Se compromete con el otro cercano y le ayuda en } \\
\text { su circunstancia concreta; se preocupa de asuntos } \\
\text { cercanos que afectan al otro (educando) tales como: } \\
\text { familia, barrio, pueblo, buscando un orden justo y el } \\
\text { bien común de todos (justicia social). }\end{array}$ \\
\hline & & \multirow{5}{*}{$\begin{array}{c}\text { Relación } \\
\text { interpersonal } \\
\text { con el alumno }\end{array}$} & $\begin{array}{l}\text { Capacidad de } \\
\text { diálogo }\end{array}$ & $\begin{array}{l}\text { Se convierte en escucha atenta, no pasiva. El diálogo } \\
\text { es escucha recíproca y búsqueda de la verdad. } \\
\text { Estar dispuesto al entendimiento a fin de llegar a un } \\
\text { mutuo acuerdo en la verdad. }\end{array}$ \\
\hline & & & Acogida & $\begin{array}{l}\text { La acogida surge de la necesidad de que el otro } \\
\text { precisa de un «refugio", un slugar cálido", se manifiesta } \\
\text { en la relación con el alumno en doble sentido: pasivo } \\
\text { (lo acepta, escucha y reconoce en su dignidad de } \\
\text { ser humano) y activo (procura atención y cuidado } \\
\text { responsable). }\end{array}$ \\
\hline & & & Guía & $\begin{array}{l}\text { Acompaña al alumno en su construcción personal. } \\
\text { Nada de éste es ajeno al profesor-educador. Genera } \\
\text { un ambiente de confianza con los alumnos favorable } \\
\text { para los aprendizajes y para la convivencia en el } \\
\text { centro de enseñanza. Acompañar al alumno es } \\
\text { inspirar confianza, dar de su tiempo al otro-educando } \\
\text { (quedándose después de clase, dispuesto a prestarle } \\
\text { ayuda más allá de lo legalmente establecido, etc.); es } \\
\text { despertar alo que uno tiene en sus adentros» (hacer } \\
\text { salir alo otro", como liberarse de lo que le impide ser } \\
\text { humano); además, es apasionarle por aprender como } \\
\text { si fuera una obsesión o una búsqueda por el saber, la } \\
\text { verdad y la justicia. }\end{array}$ \\
\hline & & & $\begin{array}{l}\text { Reconoce el } \\
\text { contexto del } \\
\text { estudiante }\end{array}$ & $\begin{array}{l}\text { Toma en cuenta el equipaje sociocultural y familiar } \\
\text { del alumno porque no se educa en «tierra de nadie. } \\
\text { Reconoce al alumno como un ser histórico que vive } \\
\text { en un espacio, tiempo y contexto determinado. }\end{array}$ \\
\hline & & & $\begin{array}{l}\text { Comparte } \\
\text { experiencias de } \\
\text { vida }\end{array}$ & $\begin{array}{l}\text { Se hace presente en la vida de los alumnos. Comparte } \\
\text { lo que es, no guarda lo que piensa. Solo a partir de } \\
\text { esa "presencia donantes es posible generar vínculos o } \\
\text { relaciones interpersonales. }\end{array}$ \\
\hline
\end{tabular}




\begin{tabular}{|c|c|c|c|c|}
\hline METACATEGORÍA & CATEgoría & SuBCATEGORÍA & CARACTERÍSTICAS & INDICADORES \\
\hline \multirow{9}{*}{$\begin{array}{l}\text { Pedagogía de la } \\
\quad \text { Alteridad } \\
\text { Discurso } \\
\text { pedagógico } \\
\text { que toma como } \\
\text { punto de partida } \\
\text { la relación } \\
\text { ética que se } \\
\text { establece entre } \\
\text { el educador y el } \\
\text { alumno; por lo } \\
\text { que las acciones } \\
\text { educativas } \\
\text { emprendidas } \\
\text { por el educador } \\
\text { se centran en el } \\
\text { reconocimiento } \\
\text { del otro } \\
\text { (alumno) y } \\
\text { su singular } \\
\text { contexto, lo } \\
\text { que a su vez } \\
\text { implica asumir } \\
\text { responsabilidad } \\
\text { ante él. }\end{array}$} & \multirow{4}{*}{$\begin{array}{l}\text { Perfil del } \\
\text { estudiante }\end{array}$} & $\begin{array}{l}\text { Promotor de un } \\
\text { clima moral en } \\
\text { el aula }\end{array}$ & $\begin{array}{l}\text { Promueve } \\
\text { valores ético- } \\
\text { morales entre sus } \\
\text { alumnos }\end{array}$ & $\begin{array}{l}\text { Muestra con su comportamiento valores ético- } \\
\text { morales (responsabilidad, solidaridad, etc.). Los } \\
\text { alumnos perciben los valores del educador. }\end{array}$ \\
\hline & & & $\begin{array}{l}\text { Se preocupa por } \\
\text { su aprendizaje y } \\
\text { solicita ayuda }\end{array}$ & $\begin{array}{l}\text { No es tomado como una amenaza, un enemigo, un } \\
\text { rival o un obstáculo. Se involucra en su aprendizaje. } \\
\text { Pregunta y espera una respuesta. Suele implicarse. }\end{array}$ \\
\hline & & Agente activo & $\begin{array}{c}\text { Necesita } \\
\text { acompañamiento, } \\
\text { desea sentirse } \\
\text { valorado, } \\
\text { respetado y } \\
\text { aceptado }\end{array}$ & $\begin{array}{l}\text { No es dependiente del todo, pero aprecia que su } \\
\text { profesor lo acompañe en su proceso de aprendizaje, } \\
\text { requiere sentirse aceptado por su profesor quien lo } \\
\text { ayuda para que se ayude a sí mismo. }\end{array}$ \\
\hline & & Ser contextual & $\begin{array}{l}\text { Vive en un } \\
\text { contexto } \\
\text { determinado que } \\
\text { influye en su } \\
\text { aprendizaje }\end{array}$ & $\begin{array}{l}\text { Enfrenta situaciones personales, familiares, sociales y } \\
\text { culturales. Pertenece a una institución educativa, a un } \\
\text { barrio, una colonia, un grupo. Que forman parte de } \\
\text { su vida e influyen en ella. }\end{array}$ \\
\hline & \multirow{2}{*}{\multicolumn{2}{|c|}{ Función de la escuela }} & $\begin{array}{c}\text { Promueve valores } \\
\text { ético-morales }\end{array}$ & $\begin{array}{l}\text { Fomenta el ethos que se aprende en la vivencia de } \\
\text { situaciones concretas en las que el alumno realiza } \\
\text { comportamientos tolerantes, de ayuda gratuita al otro } \\
\text { y dar al otro, que lo posibiliten para vivir como ser } \\
\text { humano en un contexto educativo. } \\
\text { Fomenta el desarrollo del juicio crítico para que } \\
\text { los alumnos puedan actuar como ciudadanos } \\
\text { comprometidos y tomar decisiones sobre asuntos } \\
\text { públicos. }\end{array}$ \\
\hline & & & $\begin{array}{l}\text { Fomenta el } \\
\text { servicio a la } \\
\text { comunidad }\end{array}$ & $\begin{array}{l}\text { Acerca y facilita los recursos humanos y materiales } \\
\text { para promover el interés por el bien social y la justicia } \\
\text { distributiva, esto se refleja a través del desarrollo de } \\
\text { proyectos comunitarios escolares que beneficien a la } \\
\text { sociedad. }\end{array}$ \\
\hline & \multirow{3}{*}{$\begin{array}{l}\text { Función } \\
\text { de la } \\
\text { familia }\end{array}$} & $\begin{array}{c}\text { Involucramiento } \\
\text { parental }\end{array}$ & $\begin{array}{l}\text { Seguimiento a } \\
\text { la trayectoria } \\
\text { escolar de los } \\
\text { hijos }\end{array}$ & $\begin{array}{l}\text { Los padres se involucran en los resultados de } \\
\text { aprendizaje de sus hijos, juntas escolares, asesorías y } \\
\text { realización de tareas. }\end{array}$ \\
\hline & & $\begin{array}{l}\text { Clima } \\
\text { familiar }\end{array}$ & $\begin{array}{c}\text { Potencian lo } \\
\text { mejor de sus } \\
\text { hijos, ofrecen } \\
\text { amor, protección, } \\
\text { ternura, cuidado } \\
\text { y fomentan } \\
\text { valores }\end{array}$ & $\begin{array}{l}\text { La familia se vive como un entorno cálido, una esfera } \\
\text { afectiva donde se potencia el amor, la protección, la } \\
\text { ternura, el cuidado de los hijos, la comunicación. El } \\
\text { primer acercamiento a los valores se da en la familia. }\end{array}$ \\
\hline & & $\begin{array}{l}\text { Hábitos } \\
\text { familiares }\end{array}$ & $\begin{array}{l}\text { Fomentan la } \\
\text { personalización e } \\
\text { identidad familiar }\end{array}$ & $\begin{array}{l}\text { Con el aprendizaje de hábitos familiares el joven } \\
\text { se «siente en casa». La casa es espacio físico donde se } \\
\text { establecen normas y reglas de actuación. }\end{array}$ \\
\hline
\end{tabular}


Metacategoría, categorías y subcategorías se pueden codificar para su mejor manejo y uso, sobre todo cuando un modelo, como el que se presenta, se utiliza para la realización de guías para entrevistas o para el análisis de datos cualitativos. La codificación consiste en asignar un símbolo que la represente y que facilite su conteo o identificación. Por ejemplo, la metacategoría Pedagogía de la Alteridad puede recibir un símbolo que contenga las iniciales del término -PAL- o bien la categoría Perfil del Educador podría simbolizarse como PE (Osuna, Díaz, Gárate y Murillo, 2016).

Ahora bien, para el diseño de ítems en un instrumento deben considerarse los indicadores de cada categoría o subcategoría. En la Tabla 2 se muestra un ejemplo para un instrumento cuantitativo con preguntas que contemplan respuestas cerradas. En dicho ejemplo se parte de la primera categoría Perfil del Educador, subcategoría Cualidades Personales. De acuerdo a los indicadores para dicha subcategoría, se definieron tres ítems que se pueden utilizar en un cuestionario y de cuyas respuestas podremos inferir, en opinión de un alumno, si el profesor se ajusta al perfil descrito en esta subcategoría.

TABLA 2

EJEMPLO DE ELABORACIÓN DE ÍTEMS CON BASE EN INDICADORES

\begin{tabular}{|c|c|c|c|c|}
\hline CATEGORÍA & SuBCATEGORÍA & CARACTERÍSTICAS & INDICADORES & ÍTEMS \\
\hline \multirow{3}{*}{$\begin{array}{l}\text { Perfil del } \\
\text { Educador }\end{array}$} & \multirow{3}{*}{$\begin{array}{l}\text { Cualidades } \\
\text { personales }\end{array}$} & \multirow{3}{*}{$\begin{array}{c}\text { Ama la vida } \\
\text { entusiasta }\end{array}$} & $\begin{array}{l}\text { Ama la vida y } \\
\text { lo expresa con } \\
\text { sentimientos de } \\
\text { gratuidad y gratitud. }\end{array}$ & $\begin{array}{l}\text { Durante el desarrollo } \\
\text { de sus actividades } \\
\text { docentes, ¿con } \\
\text { qué frecuencia tu } \\
\text { profesor demuestra } \\
\text { entusiasmo? } \\
\text { 1. Nunca } \\
\text { 2. Algunas veces } \\
\text { 3. Siempre }\end{array}$ \\
\hline & & & $\begin{array}{l}\text { Demuestra un } \\
\text { genuino interés } \\
\text { por su labor como } \\
\text { educador y por los } \\
\text { estudiantes. }\end{array}$ & $\begin{array}{l}\text { ¿Con qué frecuencia } \\
\text { aprecias que } \\
\text { tu profesor } \\
\text { verdaderamente se } \\
\text { interesa por su labor } \\
\text { docente? } \\
\text { 1. Nunca } \\
\text { 2. Algunas veces } \\
\text { 3. Siempre }\end{array}$ \\
\hline & & & & $\begin{array}{l}\text { ¿Tu profesor cumple } \\
\text { responsablemente con } \\
\text { sus clases? } \\
\text { 1. Sí } \\
\text { 2. No }\end{array}$ \\
\hline
\end{tabular}


Finalmente, queremos añadir que el modelo categorial que se propone en este texto puede funcionar para el diseño de cuestionarios con preguntas cerradas o abiertas, escalas para medir actitudes, guías para entrevistas o incluso para analizar el contenido de una comunicación cuyo análisis se fundamente en la Pedagogía de la Alteridad. La forma y tipo de instrumento dependerá de los objetivos y preguntas de la investigación y deberá ser congruente con el diseño de la investigación, ya sea cualitativa o cuantitativa. En el caso de instrumentos cuantitativos, una vez que se termina la primera versión del mismo, deberá hacerse una validación por jueces, quienes tendrán la responsabilidad de juzgar si las preguntas o ítems realmente se corresponden con el contenido a medir y posteriormente realizar el pilotaje para identificar las preguntas que en su redacción no son claras y hacer los ajustes pertinentes, para elaborar la versión final del mismo. En el caso de guías de entrevistas cualitativas, las preguntas a profundidad deberán basarse en las categorías establecidas en el modelo antes descrito.

\section{CONCLUSIONES}

La Pedagogía de la Alteridad comprende una mirada distinta a la actual pedagogía dominante de corte positivista, que privilegia la enseñanza-aprendizaje de saberes y destrezas. Los planteamientos realizados desde esta nueva mirada pedagógica poco tienen que ver con acudir a nuevas prácticas o recursos didácticos; es decir, no demanda nuevas formas de práctica educativa, sino más bien al contrario, lo que en sí misma implica es un cambio en la forma de concebir al hombre y al mundo, una manera distinta de acercarnos al ser humano y de estar presentes en el mundo. Se trata de una filosofía de la educación y de la vida que nos hace cómplices de todo ser humano, empezando por el que tenemos más cerca, el educando.

En el ámbito iberoamericano, la Pedagogía de la Alteridad comprende un discurso pedagógico que en las últimas fechas ha cobrado relevancia y sentido, ya que rescata y configura el perfil del educador, confiriendo funciones muy particulares a la escuela y a la familia. Así, dicha pedagogía figura como un nuevo paradigma, de inspiración levinasiana, un enfoque distinto a los actualmente vigentes para una praxis e investigación educativas.

En la literatura consultada, la Pedagogía de la Alteridad suele describirse en un plano meramente teórico, donde ciertos conceptos aún no están suficientemente construidos y otros aún carecen de categorías definidas y acotadas. En consecuencia, el presente modelo conceptual de categorías comprende, a su vez, una propuesta metodológica que representa un insumo importante para las tareas asociadas al diseño y desarrollo de instrumentos de medición que se pretendan realizar del constructo Pedagogía de la Alteridad, así como para la aplicación de técnicas cualitativas como análisis de contenido o análisis del discurso.

Finalmente, la Pedagogía de la Alteridad, como propuesta educativa, requiere profundizar en los elementos teóricos de algunas de las categorías, como la función 
de la familia y de la escuela y ahondar un poco más en el perfil del estudiante. Con todo, los elementos teóricos que aporta dicho discurso son relevantes, retadores y dignos de tomarse en consideración para darle otro sentido al acto de educar. En consecuencia, esta propuesta queda abierta a enriquecimientos futuros y aportes adicionales.

\section{REFERENCIAS BIBLIOGRÁFICAS}

Creswell, J. (2009) Research Design. Qualitative, Quantitative and Mixed Methods Approaches. USA, Sage.

Gárate, A. y Ortega, P. (2013) Educar desde la precariedad. La otra educación posible. México, Ediciones CETYS Universidad.

Hernández, M. Á. (2014) La familia desde la Pedagogía de la alteridad, en Ortega Ruiz, P. (ed.) Educar en la alteridad. Colombia, Editorial REDIPE y EDITUM, 173-193.

Hernández, R.; Fernández, C. y Baptista, P. (2010) Metodología de la investigación. México, McGraw Hill.

LÉvinas, E. (1999) Ética e Infinito. Madrid, Visor.

MÈLICH, J. C. (2010) Ética de la compasión. Barcelona, Herder.

Ortega, P. (2006) Sentimientos y moral en Horkheimer, Adorno y Lévinas. Revista Española de Pedagogía, 235, 503-524.

Ortega, P. (2010) Educar es responder a la pregunta del otro. Edetania, 37, 13-31.

Ortega, P. (2011) La otra educación. México, Ediciones CeTYS.

Ortega, P. (2014) Educar es responder del otro, en Ortega Ruiz, P. (ed.) Educar en la alteridad. Colombia, Editorial REDIPE y EDITUM, 35-51.

Ortega, P. (2016) La ética de la compasión en la pedagogía de la alteridad. Revista Española de Pedagogía, 264, 243-263.

Ortega, P.; Mínguez, R. y Hernández, M. Á. (2009) Las difíciles relaciones entre familia y escuela en España. Revista Española de Pedagogía, 243, 231-254.

Osuna, C.; Díaz, K.; GÁrate, A. y Murillo, O. (2016) Variables asociadas al abandono escolar en educación media superior. Resultados de la encuesta a jóvenes que abandonaron la educación media superior en el ciclo escolar 2013. El papel de sus padres y docentes. Reporte de investigación. Mexicali: CETYs Universidad. 